\title{
Venovenous extracorporeal membrane oxygenation devices-related colonisations and infections
}

\author{
Guillemette Thomas', Sami Hraiech ${ }^{1,2}$, Nadim Cassir², Samuel Lehingue ${ }^{1,2}$, Romain Rambaud ${ }^{1,2}$, \\ Sandrine Wiramus ${ }^{3}$, Christophe Guervilly ${ }^{1}$, Fanny Klasen ${ }^{1,2}$, Mélanie Adda' ${ }^{1}$, Stéphanie Dizier ${ }^{1}$, Antoine Roch ${ }^{2,4}$, \\ Laurent Papazian ${ }^{1,2}$ and Jean-Marie Forel ${ }^{1,2^{*}}$ (]
}

\begin{abstract}
Background: Nosocomial infections occurring during extracorporeal membrane oxygenation (ECMO) support have already been reported, but few studied infections directly related to ECMO devices. This study aims to evaluate the rate of both colonisations and infections related to ECMO devices at the time of ECMO removal.

Results: We included all consecutive adult patients treated with venovenous ECMO (VV-ECMO) for at least $48 \mathrm{~h}$ during a 34-month study. At the time of ECMO removal, blood cultures, swab cultures on insertion cannula site and intravascular cannula extremity cultures were systematically performed. Each ECMO device was classified according to the infectious status into three groups: (1) uninfected/uncolonised ECMO device, (2) ECMO device colonisation and (3) ECMO device infection. Ninety-nine patients underwent $103 \mathrm{VV}-\mathrm{ECMO}$, representing $1472 \mathrm{ECMO}$ days. The ECMO device infection rate was 9.7\% (10 events), including 7 ECMO device-related bloodstream infections (6.8\%). The ECMO device colonisation rate was 32\% (33 events). No difference was observed between the three groups, regarding days of mechanical ventilation, ICU length of stay, ICU mortality and in-hospital mortality. We observed a longer ECMO duration in the ECMO device colonisation group as compared to the uninfected/uncolonised ECMO device group [12 (9-20 days) vs. 5 days ( $5-16$ days), respectively, $p<0.05]$.

Conclusions: At the time of ECMO removal, systematic blood culture and intravascular extremity cannula culture may help to diagnose ECMO device-related infection. We reported a quite low infection rate related to ECMO device. Further studies are needed to evaluate the benefits of systematic strategies of cannula culture at the time of ECMO removal.
\end{abstract}

Keywords: Venovenous extracorporeal membrane oxygenation, Device-related infections, Device-related colonisation, Infection rate, Colonisation rate

\section{Background}

Venovenous extracorporeal membrane oxygenation (VV-ECMO) has become a widely accepted treatment option for life-threatening acute respiratory failure when mechanical ventilation (MV) and adjunctive measures

\footnotetext{
*Correspondence: jean-marie.forel@ap-hm.fr

${ }^{1}$ Hôpital Nord, Réanimation des Détresses Respiratoires et des Infections Sévères, Assistance Publique-Hôpitaux de Marseille, 13015 Marseille, France

Full list of author information is available at the end of the article
}

fail to provide adequate gas exchange or when lung rest cannot be achieved due to high ventilator requirements $[1,2]$. Over the last two decades, the technique has improved significantly, and several studies have reported encouraging survival rates using VV-ECMO in adults with acute respiratory distress syndrome (ARDS) [3-6]. However, major adverse events have been described, among which infections seem to be the most frequent $[1$, 6]. In 2011, the Extracorporeal Life Support Organization (ELSO) reported an incidence of $11.7 \%$ proven infections in 20,741 ECMO cases for a rate of 15.4 per 1000 ECMO 
days [7]. To date, most of the studies described nosocomial infections or bloodstream infections (BSI) occurring during ECMO support, but very few studied infections directly related to ECMO devices. Moreover, these studies often mixed venovenous and venoarterial ECMO support, which are very different devices regarding the type of patients, the duration of ECMO and the cannulation procedure $[8,9]$.

The main objective of this study was to evaluate the rates of both infections and colonisations related to ECMO devices in VV-ECMO adult patients at the time of ECMO removal.

\section{Methods}

\section{Study design}

An epidemiologic, prospective, observational study was conducted in the 14-bed medical intensive care unit (ICU) of a teaching hospital (Hôpital Nord, Marseille, France), a regional referral centre for the treatment of acute severe respiratory failure. The study was approved by the ethical committee of the «Sociéte de Réanimation de Langue Française». According to French law, no consent for the study was required because it did not modify existing diagnostic or therapeutic strategies.

\section{Patients and ECMO indications}

We prospectively included all consecutive adult patients treated with VV-ECMO for at least $48 \mathrm{~h}$ during a 34-month study. The ECMO-based programme includes a mobile unit that is able to initiate ECMO in referring hospitals of our region (Provence-Alpes-Côte d'Azur) before transfer to our ECMO referral centre [5].

The decision to initiate ECMO is based on the following: persistent hypoxaemia, defined as $\mathrm{PaO}_{2} /$ $\mathrm{FiO}_{2} \leq 70 \mathrm{mmHg}$ for at least $6 \mathrm{~h}$ under $\mathrm{FiO} 2$ at 1 despite optimisation of mechanical ventilation or $\mathrm{PaO}_{2} /$ $\mathrm{FiO}_{2}<100 \mathrm{mmHg}$ with a Pplat value greater than 35 $\mathrm{cmH}_{2} \mathrm{O}$ or respiratory acidosis with $\mathrm{pH} \leq 7.15$ despite a respiratory rate greater than $35 / \mathrm{min}$. Exclusion criteria for ECMO included the following: any contraindications to heparin treatment, Sequential Organ Failure Assessment (SOFA) score > 16 [10], moribund patients or those with decisions to limit therapeutic interventions.

\section{ECMO protocol}

Venovenous ECMO was instituted using percutaneous cannulation by cardiac surgeons, typically in a femoraljugular configuration but also in femoral-femoral configuration, especially when ECMO was used as a bridge to lung transplantation. We used centrifugal pumps (Bioconsole 560; Medtronic Perfusion Systems, Minneapolis, MN, USA) with a flow of 3-5 L/min in all patients. Circuits were heparin-coated and composed of Quadrox D with Bioline Coating oxygenators (Maquet, Hirrlingen, Germany), 17-25-Fr cannulae (Edwards Lifesciences, Irvine, CA, USA) and intersept polyvinyl chloride (PVC) class VI tubing (Medtronic, Watford, Hertfordshire, UK).

All cannulas were inserted using strict sterile precautions consistent with Healthcare Infection Control Practices Advisory Committee guidelines (HICPAC guidelines) [11]. For each patient, the cannula insertion site was cleansed with $96 \%$ ethanol solution containing $5 \%$ povidone-iodine. Sterile drapes were placed over the insertion site. No specific antibioprophylaxis was used at the time of cannulation. Occlusive dressings were used.

A highly trained ICU nursing staff achieved standardised cannula care every $72 \mathrm{~h}$ or earlier if clinically indicated (dirty or bloody dressing). If necessary (haemolysis, fibrinolysis), the ECMO circuit was changed using strict sterile precautions as detailed above.

When the ECMO was removed, specimens were systematically collected as follows: (a) blood cultures were sampled from the central venous catheter (CVC), arterial catheter and post-membrane oxygenator. The blood culture vials used for aerobic and anaerobic cultures (Bactec; Becton-Dickinson, Sparks, MD, USA) were incubated for 5 days. After the incubation period and automatic culture detection (Bactec 9240; Becton-Dickinson, Sparks, MD, USA), Gram staining was performed, and the samples were cultured on $5 \%$ sheep blood and chocolate agar plates at $37{ }^{\circ} \mathrm{C}$ under aerobic and anaerobic atmospheric conditions for all positive blood cultures. (b) Swabs were sampled on the drainage and return cannula site skin just before cleaning with $5 \%$ povidone-iodine antiseptic. The culture technique is described as follows. (c) The intravascular extremity of the drainage and return cannula were cut in a sterile manner and analysed by a culture technique described as follows. The extremities of the cannulas, the central venous and the arterial catheter tips when removed, were mixed with tryptic soy broth; $10 \mu \mathrm{L}$ of each mixture was then cultured on chocolate agar plates at $37{ }^{\circ} \mathrm{C}$ under aerobic atmospheric conditions. Swab samples were semi-quantitatively processed immediately by streaking the entire surface of the plates. Identification was performed when a culture yielded at least $10^{3}$ colony-forming units $(\mathrm{CFU}) / \mathrm{mL}$. Matrixassisted laser desorption/ionisation time-of-flight mass spectrometry (MALDI-TOF MS) was used for the bacterial identification as previously described [12].

\section{Definition of ECMO device colonisation and infection}

The definitions of ECMO device colonisation or infection were adapted from French and American central line-associated bloodstream infection guidelines [13, 14]. These definitions concern the central line defined as an intravascular catheter that terminates at or close 
to the heart or in one of the great vessels excluding ECMO devices. Thus, the following definitions were used: (a) cannula colonisation (CC) was defined as a positive quantitative intravascular extremity culture ( $\geq 10^{3} \mathrm{CFU}$ ). (b) Skin colonisation (SC) was a positive quantitative swab culture ( $\geq 10^{3} \mathrm{CFU}$ ). (c) Not related ECMO device bacteraemia was defined as one or more positive blood cultures with negative cannula colonisation and another infectious site responsible for bacteraemia. (d) Contamination was defined as one positive blood culture for common skin contaminants [14, 15]. (e) ECMO device infection (ED-I) corresponded to: (e.1) ECMO device-related blood stream infection (EDRBSI), which was a combination of one or more positive blood cultures (from the CVC, arterial catheter or postmembrane oxygenator) sampled immediately before or within $48 \mathrm{~h}$ after ECMO removal, a quantitative intravascular cannula extremity positive culture for the same micro-organism(s) and no other infection explaining the positive blood culture; (e.2) cannula infection (CI), which was considered in cases of a positive quantitative intravascular cannula extremity culture, negative blood culture and systemic infectious signs in the absence of any other infection. CI was also considered in case of a positive quantitative intravascular cannula extremity culture and local infection signs (local purulence or infection signs at insertion site); (e.3) in patients with blood culture and/or quantitative intravascular cannula portion culture positive for coagulase-negative staphylococci, EDR-BSI and CI were considered depending on clinical features (fever, sepsis, septic shock) within $48 \mathrm{~h}$ after ECMO removal and on clinical evolution under specific treatment if introduced by the clinician.

An adjudication committee, including one infectious disease specialist and three intensivists, retrospectively classified each case into three categories: (1) uninfected/ uncolonised ECMO device (U-I/C ED), including sterile samples, skin colonisation, blood culture contamination and not related ECMO device bacteraemia; (2) ECMO device colonisation (ED-C), including cannula colonisation associated or not with skin colonisation; (3) ECMO device infection (ED-I), including EDR-BSI and CI as previously defined.

\section{Collected data}

Prospectively collected data included demographic data; body mass index (BMI); severity of illness as assessed by the Simplified Acute Physiology Score (SAPS) II [16] and SOFA score at ICU admission [10]; major comorbidities; indication for ECMO; site of cannulation; site of ECMO implantation; ECMO system exchange; ECMO transfusion (blood, platelets and plasma), pre- and per-ECMO steroid use; pre- and per-ECMO antibiotics use; duration of both ECMO and mechanical ventilation; outcome (ICU and hospital mortalities, ventilator and ECMOfree days at both day 28 and day 90, ICU length of stay); and nosocomial infections, primary bloodstream infections or fungaemia during ECMO support. Nosocomial infection definitions agreed with those of the Centers for Disease Control and Prevention National Nosocomial Infections Surveillance System [17]. Ventilator-associated pneumonia (VAP) was diagnosed according to previously published criteria [18].

\section{End points}

The primary end points were the rates of ECMO device infection or colonisation at the time of ECMO removal. Secondary end points were the rate of skin colonisation and outcomes, such as ICU length of stay, ICU mortality, in-hospital mortality and day-90 mortality, day- 28 and day-90 ventilator and ECMO-free days.

\section{Statistical analysis}

Descriptive statistics included percentages for categorical variables and medians and interquartile ranges for continuous variables. Comparisons between the three categories (U-I/C ED, ED-C and ED-I) for continuous variables were made using the Kruskal-Wallis test with a post hoc method for multiple comparisons (step-up Simes method to calculate adjusted $p$ value). Comparisons between the three categories (U-I/C ED, ED-C and ED-I) for categorical variables were made using the Pearson Chi-square test for trend. A multinomial logistic regression procedure was performed to identify factors associated with ED-I or ED-C. The U-I/C ED group was used as the reference group. All of the variables with $p$ value $<0.20$ (gender, body mass index, statin therapy, per-ECMO plasma transfusion, reason for ECMO, location of ECMO cannulation, type of cannulation, preECMO antibiotic and ECMO duration) were included in the model. The Fleiss' kappa was calculated to evaluate the reliability agreement between the 4 experts regarding the classification of each ECMO case. A $p$ value $<0.05$ was considered significant. The statistical analysis was conducted using SPSS, version 20.0 (NY, USA).

\section{Results}

Patients

During the study period, 105 patients underwent 109 VV-ECMO (Fig. 1). Four patients underwent $2 \mathrm{VV}$ ECMO during the same ICU stay with an interval of at least 2 days between each ECMO implantation. Finally, 103 VV-ECMO were analysed (representing 1472 ECMO days). The median age was 49 years (38-62), and the most frequent reason for ECMO was ARDS (77.6\%). Fifty-three patients were referred to our ECMO centre 


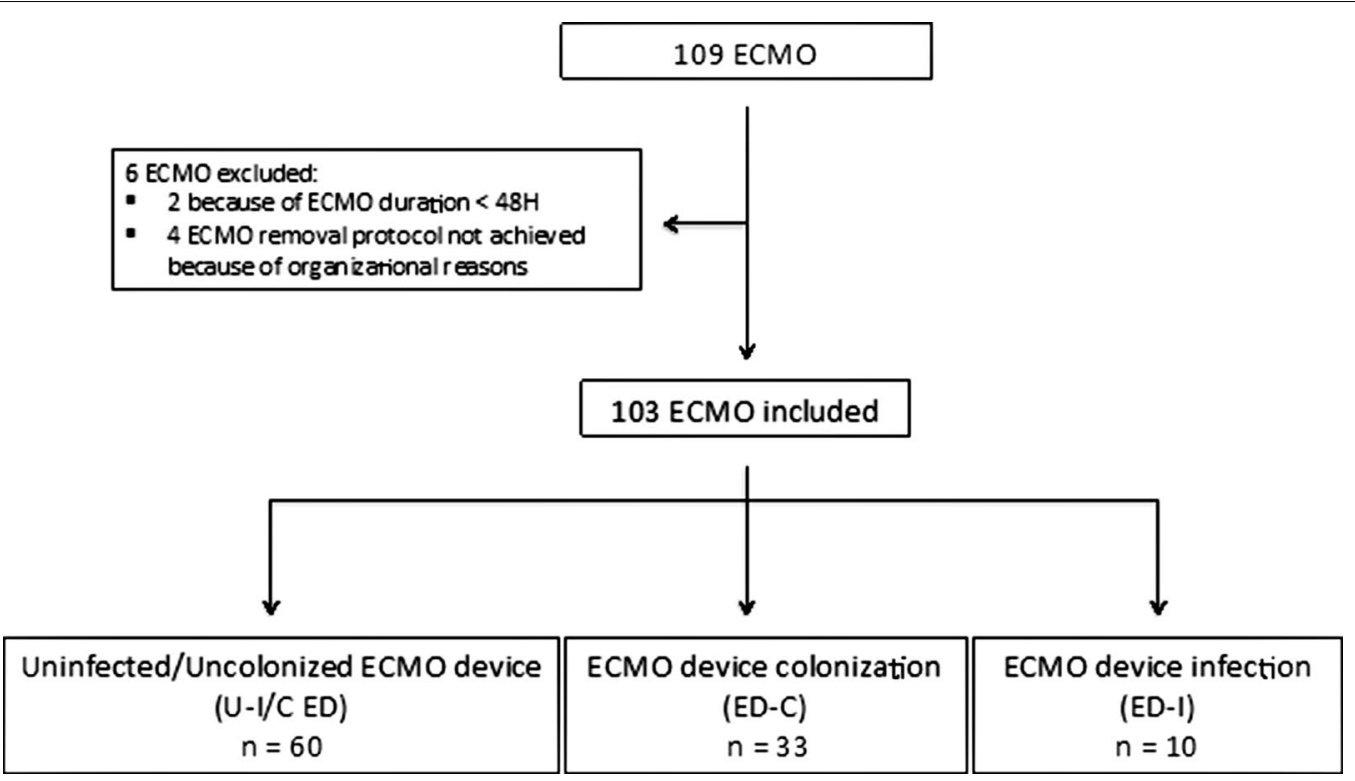

Fig. 1 Study flow chart. ECMO, extracorporeal membrane oxygenation

and transported by our mobile team. The median ECMO duration was 11 days (6-18 days). A total of 63 circuit changes were done in $38 \mathrm{VV}$-ECMO. General characteristics of each group are provided in Table 1.

\section{ECMO device colonisation and infection (Fig. 2)}

At the time of ECMO removal, the rate of ECMO device colonisation (ED-C) was 32\% (33 events). The rate of ECMO device infection (ED-I) was 9.7\% (10 events), including 7 ECMO device-related bloodstream infections (6.8\%). No patient presented with insertion site infectious signs at any moment during ECMO support or within the 48 -h period following ECMO removal. The uninfected/uncolonised ECMO device (U-I/C ED) rate was 58.3\% (60 of 103). Fleiss' kappa coefficient was 0.94 (standard error, 0.04), corresponding to strong agreement between the experts regarding the classification.

A total of 127 femoral cannulas were inserted. In all, 22\% (28 of 127) of the cultures were positive for at least one micro-organism compared with $35.4 \%$ of the cultures (28 of 79) regarding the jugular site $(p=0.052)$. Microorganisms responsible for ED-C and ED-I are detailed in Fig. 3 and Additional file 1: Table S1. Coagulase-negative staphylococcus was the most frequent organism responsible for ED-I (8/10, 80\%) and ED-C (20/33, 60.6\%). The details of blood culture results are summarised in Additional file 2: Table S2.

We observed a longer ECMO duration in the ED-C group compared with the U-I/C ED group [12 days
(9-20 days) versus 5 days (5-16 days), respectively, $p<0.05]$. Using multivariate analysis, we did not identify any factor associated with ED-C or ED-I (Additional file 3: Table S3).

\section{Skin colonisation}

The skin colonisation rate was $23.3 \%$ (24 events). When cannula colonisation was observed, concomitant skin colonisation was present in $42.4 \%$ of cases (14 of 33), with the same micro-organism in $71.4 \%$ of cases (10 of 14). Considering ED-I, no concomitant skin colonisation was observed. No differences were noted regarding skin colonisation between femoral and jugular sites $(22 / 127$, $17.3 \% ; 14 / 79,17.7 \%$, respectively, $p=0.91$ ).

\section{Outcome}

Fifty-two patients died in the ICU (50.5\%) and 58 during hospitalisation (56.3\%). No difference was observed among the three categories (U-I/C ED, ED-C and ED-I) regarding ICU length of stay, ICU mortality, in-hospital mortality and day-90 mortality (Table 2 ).

A total of 27 patients underwent at least one nosocomial infection other than ED-I, without differences among the three groups $(p=0.30)$. Forty-four nosocomial infections, excluding ED-I, occurred during the 103 VV-ECMO supports, corresponding to 29.9 infectious episodes per 1000 ECMO days. Ventilator-associated pneumonia (VAP) was the most frequent nosocomial infection (45.5\%), followed by primary bloodstream infection (36.4\%) (Additional file 4: Table S4). 
Table 1 General characteristics of ECMO in patients without infected/colonised ECMO device, with ECMO device colonisation and ECMO device infection (at the time of ECMO removal)

\begin{tabular}{|c|c|c|c|c|}
\hline \multirow[t]{2}{*}{ Number of ECMO } & \multirow{2}{*}{$\begin{array}{l}\text { U-I/C ED } \\
60\end{array}$} & \multirow{2}{*}{$\begin{array}{l}\text { ED-C } \\
33\end{array}$} & \multirow{2}{*}{$\begin{array}{l}\text { ED-I } \\
10\end{array}$} & \multirow[t]{2}{*}{$P$ value $^{b}$} \\
\hline & & & & \\
\hline Age (years) & $48(37-61)$ & $57(47-63)$ & $43(41-63)$ & 0.278 \\
\hline Male $(n, \%)$ & $35(58.3)$ & $23(69.7)$ & $8(80)$ & 0.122 \\
\hline $\mathrm{BMI}\left(\mathrm{kg} / \mathrm{m}^{2}\right)$ & $24(22-29)$ & $27(24-31)$ & $26(24-27)$ & 0.183 \\
\hline SOFA score ${ }^{c}$ & $10(7-12)$ & $9(7-14)$ & $9(7-10)$ & 0.607 \\
\hline SAPS $\|^{C}$ & $44(39-56)$ & $47(38-57)$ & $46(36-53)$ & 0.833 \\
\hline \multicolumn{5}{|l|}{ Underlying condition } \\
\hline Diabetes mellitus & $9(15)$ & $4(12.1)$ & 0 & 0.233 \\
\hline Renal insufficiency & 0 & $2(6.1)$ & 0 & 0.300 \\
\hline $\begin{array}{l}\text { Immunocompro- } \\
\text { mised }^{\text {d }}\end{array}$ & $5(8.3)$ & $6(18.2)$ & $1(10)$ & 0.402 \\
\hline COPD & $5(8.3)$ & $2(6.1)$ & 0 & 0.349 \\
\hline Solid tumour & $9(15)$ & $4(12.1)$ & $2(20)$ & 0.906 \\
\hline Cirrhosis & $2(3.3)$ & 0 & 0 & 0.272 \\
\hline Statin therapy & $8(13.3)$ & $2(6.1)$ & 0 & 0.118 \\
\hline $\begin{array}{l}\text { ICU stay before ECMO } \\
\text { centre admission }\end{array}$ & $2(0-8)$ & $5(1-10)$ & $3(0-4)$ & 0.237 \\
\hline \multicolumn{5}{|l|}{ Reason for $\mathrm{ECMO}^{\mathrm{e}}$} \\
\hline ARDS & $42(70)$ & $28(84.8)$ & $10(100)$ & $0.011^{*}$ \\
\hline CAP & 18 & 13 & $5(50)$ & \\
\hline NP & 20 & 13 & $4(40)$ & \\
\hline Extrapulmonary & 4 & 2 & $1(10)$ & \\
\hline $\begin{array}{l}\text { Bridge to lung trans- } \\
\text { plantation }\end{array}$ & $2(6.7)$ & $2(6.1)$ & 0 & 0.965 \\
\hline $\begin{array}{l}\text { Primary graft dysfunc- } \\
\text { tion }\end{array}$ & $14(23.3)$ & $3(9.1)$ & 0 & $0.023^{*}$ \\
\hline \multicolumn{5}{|l|}{ ECMO characteristics } \\
\hline Mobile ECMO team & $27(45)$ & $21(63.6)$ & $5(50)$ & 0.272 \\
\hline \multicolumn{5}{|c|}{ Location of ECMO cannulation } \\
\hline ICU & $44(73.3)$ & $31(93.9)$ & $10(100)$ & $0.005^{\# *}$ \\
\hline Operating room & $16(26.7)$ & $2(6.1)$ & 0 & \\
\hline $\begin{array}{l}\text { Per-ECMO blood } \\
\text { transfusion }\end{array}$ & $9(4-21)$ & $8(5-17)$ & $9(6-16)$ & 0.934 \\
\hline $\begin{array}{l}\text { Per-ECMO platelet } \\
\text { transfusion }\end{array}$ & $1(0-4)$ & $1(0-4)$ & $1(0-1)$ & 0.651 \\
\hline $\begin{array}{l}\text { Per-ECMO plasma } \\
\text { transfusion }\end{array}$ & $2(0-10)$ & $0(0-4)$ & $0(0-4)$ & 0.197 \\
\hline Pre-ECMO steroids & $14(23.3)$ & $8(24.2)$ & $2(20)$ & 0.903 \\
\hline Per-ECMO steroids & $31(51.7)$ & $15(45.5)$ & $3(30)$ & 0.214 \\
\hline Pre-ECMO antibiotics ${ }^{f}$ & $48(80)$ & $29(87.9)$ & $10(100)$ & 0.085 \\
\hline Per-ECMO antibiotics ${ }^{g}$ & $58(96.7)$ & $33(100)$ & $10(100)$ & 0.272 \\
\hline $\begin{array}{l}\text { Antibiotics at the time } \\
\text { of ECMO removal }\end{array}$ & $48(80)$ & $30(90.9)$ & $5(50)$ & 0.314 \\
\hline $\mathrm{BSI}$ during $\mathrm{ECMO}^{\mathrm{h}}$ & $10(16.7)$ & $8(24.2)$ & $2(20)$ & 0.525 \\
\hline \multicolumn{5}{|l|}{ Cannulation } \\
\hline Femoro-femoral & $19(31.7)$ & $5(15.2)$ & 0 & $0.011^{*}$ \\
\hline Femoro-jugular & $41(68.3)$ & $28(84.8)$ & $10(100)$ & \\
\hline
\end{tabular}

Table 1 continued

\begin{tabular}{lllll}
\hline $\begin{array}{lll}\text { Number of ECMO } \\
\text { a }\end{array}$ & $\begin{array}{l}\text { U-I/C ED } \\
\mathbf{6 0}\end{array}$ & $\begin{array}{l}\text { ED-C } \\
\mathbf{3 3}\end{array}$ & $\begin{array}{l}\text { ED-I } \\
\mathbf{1 0}\end{array}$ & $\boldsymbol{P}^{\text {value }}$ \\
\hline $\begin{array}{l}\text { ECMO circuit change } \\
(\geq 1)\end{array}$ & $24(40)$ & $12(36.4)$ & $2(20)$ & 0.278 \\
\begin{tabular}{l} 
ECMO duration (days) \\
\hline
\end{tabular} & $7.5(5-16)$ & $12(9-20)$ & $13(11-17)$ & $0.021^{\#}$ \\
\hline
\end{tabular}

Data are provided as no. (\%) of ECMO or median value (interquartile range)

$A R D S$ acute respiratory distress syndrome, $B M I$ body mass index, $C A P$ community-acquired pneumonia, COPD chronic obstructive pulmonary disease, $E C M O$ extracorporeal membrane oxygenation, ICU intensive care unit, $N P$ nosocomial pneumonia, SAPS I/ Simplified Acute Physiology Score, SOFA sepsisrelated organ failure assessment, $U-I / C E D$ uninfected/uncolonised ECMO device, $E D-C E C M O$ device colonisation, ED-/ ECMO device infection

${ }^{*} p<0.05$, comparison between U-I/C ED and ED-I

\# $p<0.05$, comparison between U-I/C ED and ED-C

a Among the 99 patients, 4 underwent 2 ECMO during their ICU stay corresponding to $103 \mathrm{VV}$-ECMO

b $p$ value corresponds to the comparison between the three categories (U-I/C $\mathrm{ED}, \mathrm{ED}-\mathrm{C}, \mathrm{ED}-\mathrm{I})$

c Calculated at ICU admission

${ }^{d}$ Includes patients with human immunodeficiency virus, solid organ transplantation or haematological malignancy and those receiving chemotherapy, immunosuppressive agents or long-term corticosteroid therapy

e For 2 patients, ECMO reason was thoracic surgery

f Pre-ECMO antibiotics correspond to antibiotics received for at least $24 \mathrm{~h}$ before ECMO implantation

9 Per-ECMO antibiotics correspond to antibiotics received immediately after ECMO implantation

${ }^{\mathrm{h}}$ Bloodstream infection (BSI) under ECMO includes primary and secondary bloodstream infections

\section{Discussion}

To our knowledge, this is the first study that systematically analysed ECMO devices at the time of ECMO removal, providing the rate of ECMO device-related infection and colonisation in an adult cohort of venovenous ECMO supports. Our results indicate that the ECMO device infection rate (cannula infections or ECMO device-related bloodstream infections) was 9.7\%, and the ECMO device colonisation rate was $32 \%$. Indeed, most of the studies related the incidence of nosocomial infections and bloodstream infections while on venoarterial or venovenous ECMO support, and these studies often used paediatric cohorts $[7-9,19,20]$. The originality of our work was to assess the infection and colonisation rates directly associated with the ECMO device. Schmidt et al. [9] reported a large series of 220 venoarterial ECMO support cases in adult cardiogenic shock and described 21 (9.5\%) cannula infections, defined as the association of local signs of infection at the access site with a positive culture of subcutaneous needle aspirate from the cannula site. One major difference with this study is that VA-ECMO cannulation was performed 


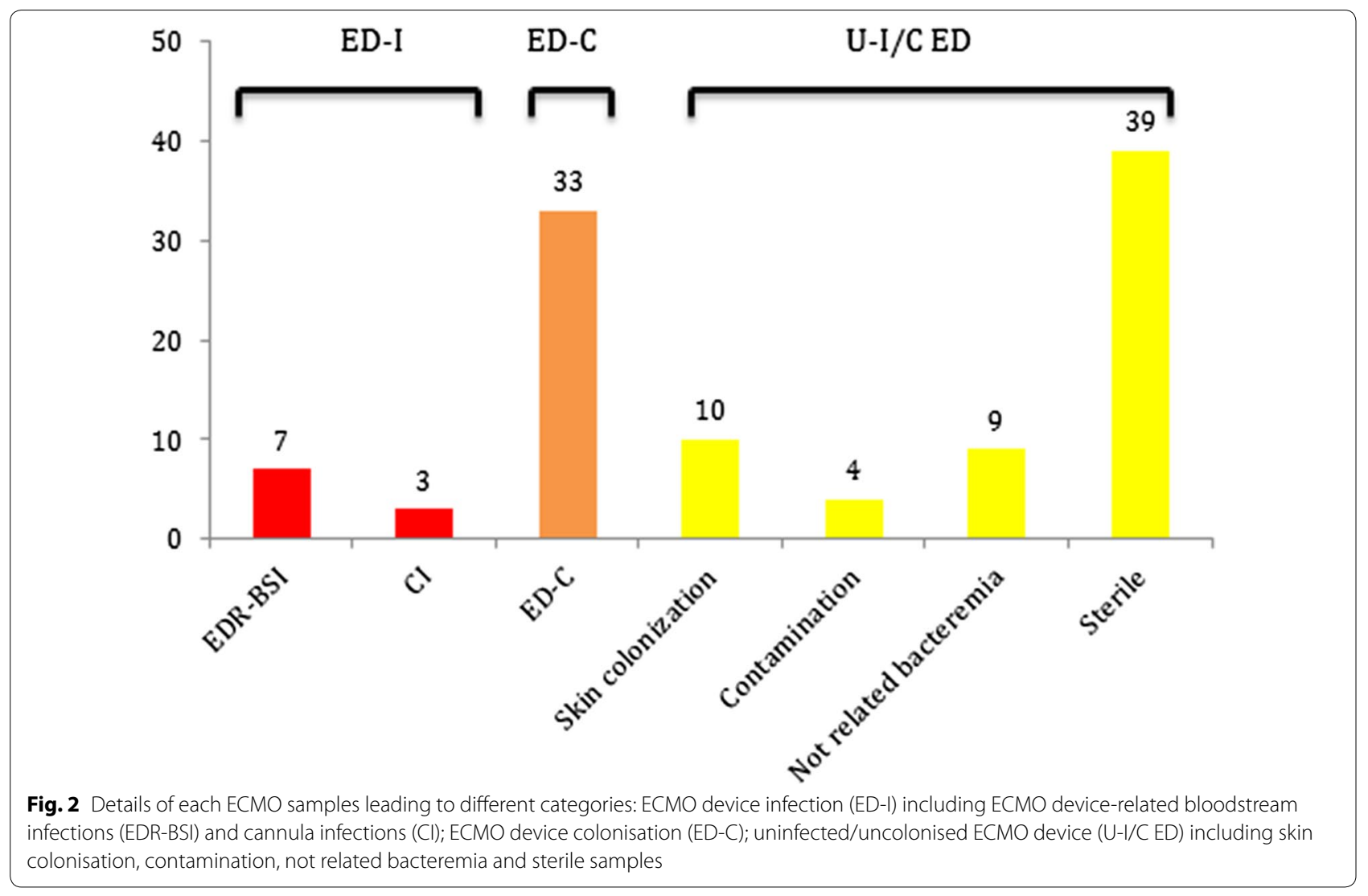

with an invasive surgical procedure, especially in the case of central VA-ECMO, whereas VV-ECMO cannulation only requires a percutaneous procedure (which was the case for all of our patients). Furthermore, the definition of cannula infection was different and could reflect surgical site infection rather than cannula infection in this study. Of note, none of our patients presented with cannula local infectious signs at any moment during ECMO support and even during the 48 following hours. Lubnow et al. described technical complications leading to system exchange in 265 adult patients treated with VVECMO support for acute respiratory failure. Eighty-three patients underwent at least one system change, and 4 of these cases (5\%) were due to suspected infection [21]. More recently, Hahne et al. evaluated the culture results of 186 cannulae removed from 94 patients who benefited from extracorporeal circulation for lung or cardiac assistance. Fifteen patients $(16 \%)$ presented cannula-related infection [22].

ECMO device-related infections may involve the drainage cannula, the return cannula or the membrane oxygenator (MO). Thus, Kuehn et al. [23] hypothesised that the artificial surfaces of the ECMO circuit, particularly the $\mathrm{MO}$, could be the target of microbial adhesion and colonisation, favouring the development of ECMO-related bloodstream infection. The overall patient-based positivity by PCR was $45 \%$. In the present study, membrane oxygenator infection was difficult to assess. We performed post-membranous blood culture on the day of removal (Additional file 4: Table S4), which was positive in 15 cases and allowed the diagnosis of ECMO device-related bloodstream infection (EDR-BSI) in only one case.

Our results revealed a longer ECMO duration in the ED-C group compared with the U-I/C ED group. Catheter duration is a well-known risk factor for catheter colonisation or catheter-related bloodstream infection [24]. Moreover, the prevalence of nosocomial infection increases with ECMO duration [7, 9]. No difference was observed between the U-I/C ED group and ED-I, which is probably due to the small number of patients in this group. At least, skin colonisation was not observed in the 10 ED-I, suggesting that ECMO device-related infections could originate from haematogenous contamination or circuit changes although our data cannot confirm this hypothesis (Table 1).

We reported a higher proportion of primary graft dysfunction, femoro-femoral cannulation and cannulation in the operating room in the U-I/C ED group compared with the ED-C group and/or the ED-I group. This finding 


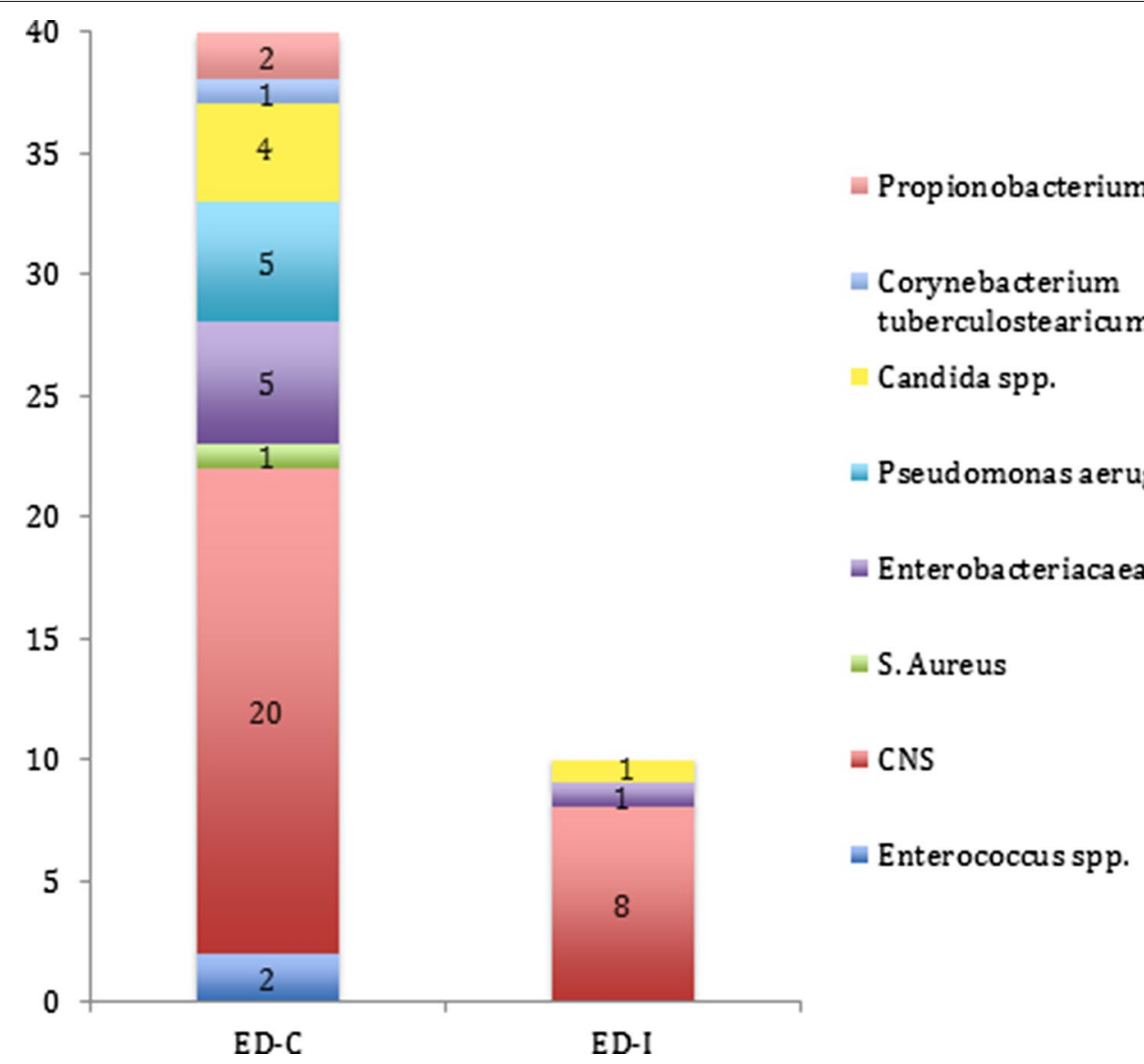

Fig. 3 Micro-organisms associated with ECMO device colonisations and infections. CNS Coagulase-negative staphylococci. Seven cannulas were colonised with two different micro-organisms corresponding to 33 cannula colonisations and a total number of 40 micro-organisms

can be easily explained by the fact that all patients with primary graft dysfunction benefited from ECMO cannulation at the end of the lung transplant, in the operating room, and with femoro-femoral cannulation due to surgical technical reasons. Moreover, the duration of ECMO was reduced for primary graft dysfunction indication compared with ARDS indication [5 (4-6) vs. 12 days (7-18), $p<0.001$ data not shown]. Thus, the differences observed between the different groups are probably the result of significant differences of ECMO duration.

Our study described a very much higher rate of infection with ECMO device than with central venous catheter. During the study period, central venous catheter-related infection rate was 1.2 per 1000 catheter days. ECMO cannula size is bigger (17-25 Fr) and duration of ECMO longer than central venous catheter. Moreover, cannula change is highly problematic because of the few vascular accesses and due to patient's vital dependence on ECMO support.

Antibiotic prophylaxis to prevent nosocomial infections in ECMO patients remains highly controversial due to the emergence of resistance to antibiotics and Clostridium difficile-associated colitis [25]. Daily surveillance blood cultures have been proposed as an alternative to antibiotic prophylaxis and remain a routine practice in many ECMO centres, but this strategy is costly and resource consuming $[9,19,26]$. Wide variability in practice is also noted regarding the prevention of nosocomial and bloodstream infections for patients requiring ECMO. In a recent survey of the ELSO members interested in nosocomial bloodstream infection prevention practice, only one-quarter of respondents reported the use of a bundle or checklist during ECMO cannula insertion and less than half utilise a bundle or checklist for cannula maintenance [27]. In our opinion, if daily surveillance blood culture in patients with ECMO support should not be recommended, the systematic culture of vascular cannula portions associated with blood culture performed at the time of removal may help the clinician to make the diagnosis of ECMO device-related infection and guide the antibiotics prescription. Finally, we did not use chlorhexidine antiseptic protocol at the time of 
Table 2 Outcome of extracorporeal membrane oxygenation in patients without infected/colonised ECMO device, with ECMO device colonisation and ECMO device infection (at the time of ECMO removal)

\begin{tabular}{lllll}
\hline Number of ECMO & U-I/C ED & ED-C & ED-I & p value \\
& $\mathbf{6 0}$ & $\mathbf{3 3}$ & $\mathbf{1 0}$ & \\
\hline ICU LOS & $25(14-39)$ & $24(20-33)$ & $30(23-37)$ & 0.614 \\
ICU mortality & $27(45)$ & $21(63.6)$ & $4(40)$ & 0.559 \\
Day-90 mortality & $28(46.7)$ & $22(66.7)$ & $4(40)$ & 0.622 \\
In-hospital mortality & $32(53.3)$ & $22(66.7)$ & $6(60)$ & 0.896 \\
Days of MV & $23(12-37)$ & $24(18-32)$ & $28(23-30)$ & 0.671 \\
VFD day 28 & $0(0-1)$ & $0(0-0)$ & $0(0-0)$ & 0.385 \\
VFD day 90 & $1(0-60)$ & $0(0-35)$ & $9(0-52)$ & 0.506 \\
ECMOFD day 28 & $13(0-21)$ & $3(0-18)$ & $7(0-14)$ & 0.169 \\
ECMOFD day 90 & $63(0-83)$ & $9(0-78)$ & $62(0-76)$ & 0.156 \\
ECMO weaning & $43(71.7)$ & $17(51.5)$ & $7(70)$ & 0.283
\end{tabular}

Data are provided as no. (\%) of ECMO or median value (interquartile range) ECMO extracorporeal membrane oxygenation, ECMOFD ECMO-free day, ICU intensive care unit, LOS length of stay, $M V$ mechanical ventilation, $V F D$ ventilatorfree day, U-I/C ED uninfected/uncolonised ECMO device, ED-C ECMO device colonisation, $E D-/ E C M O$ device infection

a Among the 99 patients, 4 underwent 2 ECMO during their ICU stay corresponding to $103 \mathrm{VV}$-ECMO

cannula insertion and for the standardised cannula care. Chlorhexidine-impregnated dressing for cannula dressing was not used in our study which could be evaluated in the future to evaluate the impact on the rate of ECMO device colonisation and infection.

Our study presents several limitations. There is currently no consensus on the definition of ECMO devicerelated infection. Indeed, the Centers for Disease Control and Prevention (CDC) guidelines have established a clear definition of central line-related infection or blood stream infections that precisely exclude ECMO devices [14]. Moreover, the definitions that include differential time to blood culture positivity appear to be inappropriate given the impossibility and danger of performing blood culture in ECMO cannulae $[13,28]$. We have decided to use the threshold of $10^{3}$ colony-forming unit for the positivity of the device culture, which is derived from catheter infection literature but not validated for the ECMO device so far. At least, our study focused on ECMO device infection and colonisation at the time of removal and not during the ECMO support period. Moreover, the huge majority of our patients were receiving antibiotics at the time of ECMO insertion and during the ECMO run. These two last elements could have led to possible underestimation of the number of infections and colonisations. We did not collected data regarding dressing disruption or changes that might help to explain the differences between the rate of colonisation and the rate of infection. Using a multinomial logistic regression procedure, we failed to establish factors associated with ECMO device colonisation or infection, probably because of the cohort size.

\section{Conclusions}

At the time of ECMO removal, systematic blood culture and intravascular extremity cannula culture may help to diagnose ECMO device-related infection. We reported a quite low infection rate related to the devices. Further studies are needed to evaluate the benefits of systematic strategies of cannula culture at the time of ECMO removal.

\section{Additional files}

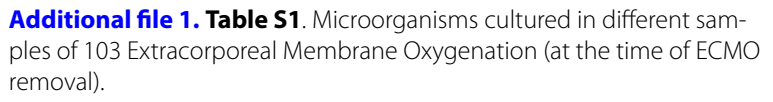

Additional file 1. Table S1. Microorganisms cultured in different samples of 103 Extracorporeal Membrane Oxygenation (at the time of ECMO removal).

Additional file 2. Table S2. Microorganisms cultured in blood culture (at the time of ECMO removal).

Additional file 3. Table S3. Nosocomial infections during ECMO support of Extracorporeal Membrane Oxygenation (ECMO) in patients without infected/colonized ECMO device (U-I/C ED), with EMCO device colonization (ED-C) and ECMO device infection (ED-I) (at the time of ECMO removal).

Additional file 4. Table S4. Multivariate analysis of factors associated with ECMO device infection (ED-I) or colonization (ED-C) at the time of ECMO removal.

\section{Abbreviations}

ARDS: acute respiratory distress syndrome; BC: blood culture; BMl: body mass index; BSI: bloodstream infections; CC: cannula colonisation; Cl: cannula infection; CFU: colony-forming units; CVC: central venous catheter; ELSO: Extracorporeal Life Support Organization; ECMO: extracorporeal membrane oxygenation; ED-C: ECMO device colonisation; ED-I: ECMO device infection; EDR-BSI: ECMO device-related blood stream infection; HICPAC Guidelines: Healthcare Infection Control Practices Advisory Committee Guidelines; ICU: intensive care unit; MALDI-TOF MS: matrix-assisted laser desorption/ionisation time-of-flight mass spectrometry; MV: mechanical ventilation; PEEP: positive end-expiratory pressure; Pplat: plateau pressure; SAPS: Simplified Acute Physiology Score; SK: akin colonisation; SOFA: Sequential Organ Failure Assessment; U-I/C ED: uninfected/uncolonised ECMO device; VAP: ventilator-associated pneumonia; VT: tidal volume; $\mathrm{V}$-ECMO: venovenous extracorporeal membrane oxygenation.

\section{Authors' contributions}

JMF and GT designed the work. SL, RR, SW, FK and SD collected the data. GT, JMF, LP analysed, interpreted the patient data and wrote the manuscript. SH, NC, MA and CG examined the data to class the type of infection. AR revised the manuscript. All authors read and approved the final manuscript.

\section{Author details}

${ }^{1}$ Hôpital Nord, Réanimation des Détresses Respiratoires et des Infections Sévères, Assistance Publique-Hôpitaux de Marseille, 13015 Marseille, France. 2 URMITE, UMR CNRS 7278, Faculté de Médecine, Aix-Marseille Université, 13005 Marseille, France. ${ }^{3}$ Hôpital de la Conception, Réanimation des brulés Assistance Publique-Hôpitaux de Marseille, 13005 Marseille, France. ${ }^{4}$ Hôpital Nord, Service des Urgences, Assistance Publique-Hôpitaux de Marseille,

13015 Marseille, France.

\section{Acknowledgements}

This manuscript was edited for proper English language, grammar, punctuation, spelling and overall style by one or more of the highly qualified native English-speaking editors at American Journal Experts. 


\section{Competing interests}

The authors declare that they have no competing interests.

\section{Availability of data and materials}

The data sets used and/or analysed during the current study will be available from the corresponding author on reasonable request.

\section{Consent for publication}

Not applicable.

\section{Ethics approval and consent to participate}

The study was approved by the Ethical Committee of the «Société de Réanimation de Langue Française» (CE SRLF 14-28). According to French law, no consent for the study was required because it did not modify existing diagnostic or therapeutic strategies.

\section{Funding}

Not applicable.

\section{Publisher's Note}

Springer Nature remains neutral with regard to jurisdictional claims in published maps and institutional affiliations.

Received: 6 June 2017 Accepted: 26 October 2017

Published online: 07 November 2017

\section{References}

1. Brodie D, Bacchetta M. Extracorporeal membrane oxygenation for ARDS in adults. N Engl J Med. 2011;365:1905-14. https://doi.org/10.1056/ NEJMct1103720.

2. Rehder KJ, Turner DA, Cheifetz IM. Extracorporeal membrane oxygenation for neonatal and pediatric respiratory failure: an evidence-based review of the past decade (2002-2012). Pediatr Crit Care Med J Soc Crit Care Med World Fed Pediatr Intensive Crit Care Soc. 2013;14:851-61. https:// doi.org/10.1097/PCC.0b013e3182a5540d.

3. Australia and New Zealand Extracorporeal Membrane Oxygenation (ANZ ECMO) Influenza Investigators. Extracorporeal Membrane Oxygenation for 2009 Influenza A(H1N1) Acute Respiratory Distress Syndrome. JAMA. 2009; 302:1888-1895; https://doi.org/10.1001/jama.2009.1535.

4. Camboni D, Philipp A, Lubnow M, Bein T, Haneya A, Diez C, Schmid C, Müller T. Support time-dependent outcome analysis for veno-venous extracorporeal membrane oxygenation. Eur J Cardio Thorac Surg Off J Eur Assoc Cardio Thorac Surg. 2011;40:1341-1346-1347. https://doi. org/10.1016/j.ejcts.2011.03.062.

5. Roch A, Hraiech S, Masson E, Grisoli D, Forel J-M, Boucekine M, Morera P, Guervilly C, Adda M, Dizier S, Toesca R, Collart F, Papazian L. Outcome of acute respiratory distress syndrome patients treated with extracorporea membrane oxygenation and brought to a referral center. Intensive Care Med. 2014:40:74-83. https://doi.org/10.1007/s00134-013-3135-1.

6. Fan E, Gattinoni L, Combes A, Schmidt M, Peek G, Brodie D, Muller T, Morelli A, Ranieri VM, Pesanti A, Brochard L, Hodgson C, Van Kiersbilck C, Roch A, Quintel M, Papazian L. Venovenous extracorporeal membrane oxygenation for acute respiratory failure: a clinical review from an international group of experts. Intensive Care Med. 2016;42:712-24. https://doi. org/10.1007/s00134-016-4314-7.

7. Bizzarro MJ, Conrad SA, Kaufman DA, Rycus P. Infections acquired during extracorporeal membrane oxygenation in neonates, children, and adults. Pediatr Crit Care Med J Soc Crit Care Med World Fed Pediatr Intensive Crit Care Soc. 2011;12:277-81. https://doi.org/10.1097/PCC.0b013e3181e28894.

8. Sun H-Y, Ko W-J, Tsai P-R, Sun C-C, Chang Y-Y, Lee C-W, Chen Y-C. Infections occurring during extracorporeal membrane oxygenation use in adult patients. J Thorac Cardiovasc Surg. 2010;140(1125-1132):e2. https:// doi.org/10.1016/j.jtcvs.2010.07.017.

9. Schmidt M, Bréchot N, Hariri S, Guiguet M, Luyt C-E, Makri R, Leprince P, Trouillet J-L, Pavie A, Chastre J, Combes A. Nosocomial infections in adult cardiogenic shock patients supported by venoarterial extracorporeal membrane oxygenation. Clin Infect Dis Off Publ Infect Dis Soc Am. 2012;55:1633-41. https://doi.org/10.1093/cid/cis783.

10. Vincent JL, Moreno R, Takala J, Willatts S, De Mendoça A, Bruining H, Reinhart CK, Suter PM, Thijs LG. The SOFA (Sepsis-related Organ Failure Assessment) score to describe organ dysfunction/failure. On behalf of the Working Group on Sepsis-Related Problems of the European Society of Intensive Care Medicine. Intensive Care Med. 1996;22:707-10.

11. O'Grady NP, Alexander M, Burns LA, Dellinger EP, Garland J, Heard SO, Lipsett PA, Masur H, Mermel LA, Pearson ML, Raad II, Randolph AG, Rupp ME, Saint S. Summary of recommendations: guidelines for the prevention of intravascular catheter-related infections. Clin Infect Dis Off Publ Infect Dis Soc Am. 2011;52:1087-99. https://doi.org/10.1093/cid/cir138.

12. Seng P, Drancourt M, Gouriet F, La Scola B, Fournier PE, Rolain JM, Raoult D. Ongoing revolution in bacteriology: routine identification of bacteria by matrix-assisted laser desorption ionization time-of-flight mass spectrometry. Clin Infect Dis Off Publ Infect Dis Soc Am. 2009;49:543-51. https://doi.org/10.1086/600885

13. Comité technique des infections nosocomiales et des infections liées aux soins, Ministère de la santé, de la jeunesse et des sports DGS/DHOS. http://socialsante.gouv.fr/IMG/pdf/rapport_complet.pdf. Accessed 15 June 2015

14. Centers of Disease Control and Prevention, Healthcare Infection Control Practices Advisory Committee (CDC/HIPAC). http://www.cdc.gov/hicpac/ pubs.html. Accessed 15 June 2015.

15. Hall KK, Lyman JA. Updated review of blood culture contamination. Clin Microbiol Rev. 2006;19:788-802. https://doi.org/10.1128/CMR.00062-05.

16. Le Gall JR, Lemeshow S, Saulnier F. A new Simplified Acute Physiology Score (SAPS II) based on a European/North American multicenter study. JAMA. 1993:270:2957-63.

17. Garner JS, Jarvis WR, Emori TG, Horan TC, Hughes JM. CDC definitions for nosocomial infections, 1988. Am J Infect Control. 1988;16:128-40.

18. Papazian L, Roch A, Charles PE, Penot-Ragon C, Perrin G, Roulier P, Goutorbe P, Lefrant JY, Wiramus S, Jung B, Perbet S, Hernu R, Nau A, Baldesi O, Allardet-Servent J, Baumstarck K, Jouve E, Moussa M, Hraiech S, Guervilly C, Forel JM, STATIN-VAP Study Group. Effect of statin therapy on mortality in patients with ventilator-associated pneumonia: a randomized clinical trial. JAMA. 2013;310:1692-700. https://doi.org/10.1001/ jama.2013.280031.

19. Kaczala GW, Paulus SC, Al-Dajani N, Jang W, Blondel-Hill E, Dobson S, Cogswell A, Singh AJ. Bloodstream infections in pediatric ECLS: usefulness of daily blood culture monitoring and predictive value of biological markers. The British Columbia experience. Pediatr Surg Int. 2009;25:169-73. https://doi.org/10.1007/s00383-008-2299-1.

20. Burket JS, Bartlett RH, Vander Hyde K, Chenoweth CE. Nosocomial infections in adult patients undergoing extracorporeal membrane oxygenation. Clin Infect Dis Off Publ Infect Dis Soc Am. 1999;28:828-33. https:// doi.org/10.1086/515200.

21. Lubnow M, Philipp A, Foltan M, Enger TB, Lunz D, Bein T, Haneya A, Schmid C, Riegger G, Müller T, Lehle K. Technical complications during veno-venous extracorporeal membrane oxygenation and their relevance predicting a system-exchange-retrospective analysis of 265 cases. PLoS ONE. 2014;9:e112316. https://doi.org/10.1371/journal.pone.0112316.

22. Hahne K, Horstmann C, Fischer D, Kock R, Peters G, Lebiedz P. Cannularelated infection in adult medical intensive care unit patients undergoing extracorporeal life support and extracorporeal membrane oxygenation. J Hosp Infect. 2015;91:372-4. https://doi.org/10.1016/j.jhin.2015.08.022.

23. Kuehn C, Orszag P, Burgwitz K, Marsch G, Stumpp N, Stiesch M, Haverich A. Microbial adhesion on membrane oxygenators in patients requiring extracorporeal life support detected by a universal rDNA PCR test. ASAIO J Am Soc Artif Intern Organs. 2013;59:368-73. https://doi.org/10.1097/ MAT.0b013e318299fd07.

24. Polderman KH, Girbes ARJ. Central venous catheter use. Part 2: infectious complications. Intensive Care Med. 2002;28:18-28. https://doi. org/10.1007/s00134-001-1156-7.

25. Paterson DL. "Collateral damage" from cephalosporin or quinolone antibiotic therapy. Clin Infect Dis Off Publ Infect Dis Soc Am. 2004;38(Suppl 4):S341-5. https://doi.org/10.1086/382690.

26. Kao LS, Fleming GM, Escamilla RJ, Lew DF, Lally KP. Antimicrobial prophylaxis and infection surveillance in extracorporeal membrane oxygenation 
patients: a multi-institutional survey of practice patterns. ASAIO J Am Soc Artif Intern Organs. 2011;57:231-8. https://doi.org/10.1097/ MAT.0b013e31820d19ab.

27. Glater-Welt LB, Schneider JB, Zinger MM, Rosen L, Sweberg TM. Nosocomial bloodstream infections in patients receiving extracorporeal life support: variability in prevention practices: a survey of the Extracorporeal Life Support Organization members. J Intensive Care Med. 2015; https:// doi.org/10.1177/0885066615571540
28. Mermel LA, Allon M, Bouza E, Craven DE, Flynn P, O'Grady NP, Raad II, Rinjders BJA, Sherertz RJ, Warren DK. Clinical practice guidelines for the diagnosis and management of intravascular catheter-related infection: 2009 Update by the Infectious Diseases Society of America. Clin Infect Dis Off Publ Infect Dis Soc Am. 2009:49:1-45. https://doi.org/10.1086/599376.

\section{Submit your manuscript to a SpringerOpen ${ }^{\circ}$ journal and benefit from:}

- Convenient online submission

- Rigorous peer review

- Open access: articles freely available online

- High visibility within the field

- Retaining the copyright to your article

Submit your next manuscript at $\boldsymbol{\nabla}$ springeropen.com 